\title{
The Nutritional Profile Among Children with Epilepsy at Sanglah Hospital
}

\author{
Johanes Ari Cahyo Prabowo, I Gusti Ngurah Made Suwarba ${ }^{*}$, Dewi Sutriani Mahalini \\ Department of Child Health, Faculty of Medicine Udayana, Sanglah Hospital Bali, Bali, Indonesia \\ Email address: \\ suwarbangurah@yahoo.co.id (I G. N. M. Suwarba) \\ ${ }^{*}$ Corresponding author

\section{To cite this article:} \\ Johanes Ari Cahyo Prabowo, I Gusti Ngurah Made Suwarba, Dewi Sutriani Mahalini. The Nutritional Profile Among Children with Epilepsy \\ at Sanglah Hospital. Clinical Neurology and Neuroscience. Vol. 4, No. 4, 2020, pp. 92-97. doi: 10.11648/j.cnn.20200404.15
}

Received: November 30, 2020; Accepted: December 9, 2020; Published: December 16, 2020

\begin{abstract}
One million people live with epilepsy in Indonesia. The using of antiepileptic drug for the long time can affect the nutritional and growth profile among children with epilepsy. The purpose of this study is to determine the characteristics of nutritional profile among children with epilepsy at Sanglah Hospital Denpasar. This study is an observational retrospective study using a descriptive design that examined the nutritional profile among hospitalized children with epilepsy at the pediatric neurology ward at Sanglah Hospital, Denpasar. This study was done retrospectively based on secondary data since January 1, 2017 until December 31, 2019, with 95 samples population were collected. The mean age of sample population was 5,4 years ( $\mathrm{SD} \pm 4.3$ ) with majority samples were male 60 children (63.1\%) and female were 35 children (36,9\%). The majority of samples had general epilepsy 59 children (62.1\%), followed by focal epilepsy 23 children $(24.2 \%)$ and general combined focal epilepsy 13 children (13.7\%). In this study, the most common etiology of epilepsy were idiopathic 53 children (55.8\%), followed by structural 30 children (31.6\%), infection 8 children (8.4\%), immunology and metabolic 4 children (4.2\%). The most of sample population had normal nutritional status based on waterlow method (weight for height) was $55,4 \%$ and height for age was $74,7 \%$. However, there were increasing number of overweight/obesity was 14 children $(14,7 \%)$ with history of prolonged anti epileptic drug more than 12 month that using phenobarbital, phenytoin, and valproic acid for medication. The short stature was noted among 24 children $(25,3 \%)$ of samples, with history of phenobarbital, phenytoin and carbamazepine medication. Sample population with moderate of protein energy malnutrition was 8 children $(8.4 \%)$ with dysfunction of oromotor. We conclude that almost children with epilepsy at Sanglah hospital had normal nutritional status and height stature. However regular follow up of antropometric status and diagnostic serum calcium, and folic acid should be done for early detection of overweight and obesity along with short stature.
\end{abstract}

Keywords: Nutritional Profile, Epilepsy, Antiepileptic Drugs (AED)

\section{Introduction}

Epilepsy is the most common brain disease and it frequently affects growth, developmental milestones and nutritional profile among children. Based on World Health Organization (WHO) revealed that almost 70 people live with epilepsy, and epilepsy cases that need for therapy are 8.2 per 1000 children [1]. Incidence cases of epilepsy has increased in many development countries and reach 40 cases per 100.000 children every year $[1,2]$. Study by Wieser in 2000 found that Indonesia is one of country with increasing number of epilepsy cases [3]. Incidence of epilepsy cases is $3,9-5,6$ per 1000 people with almost 1.1 millions people live with Epilepsy in Indonesia (Hui, 2004) [4]. Study by Hui, in 2004 , found that majority cases of epilepsy more frequent in children compared to adult and the most of cases occur below 1 year old.

Based on International League Against Epilepsy (ILAE) 2017, epilepsy is defined as a disease with symptom minimum of 2 episodes of unprovoked seizure occur more than 24 hours interval, or one episode of unprovoked seizure that has possibility of recurrence more than $60 \%$ within 10 years [5]. The management for epilepsy is very challenging because the duration therapy need more than 1 year and need 
adequate compliance from the children affected. The quality of life for children with epilepsy become an important factor to be discussed because it has affected many life aspects such as growth, developmental milestones and nutritional profile $[4,5]$.

The characteristics of nutritional profile among children live with epilepsy is still being discussed whether the disease itself could make obesity, or malnutrition. Pediatric nutrition management has an important role because the complication of nutritional status depend on duration management of oral antiepileptic medication [6, 7]. Based on study by Teng Yeow Tan, et al, found that long duration of antiepileptic drugs can be associated with increasing risk of obesity and atherosclerosis [8]. Study by Guo, in 2001, revealed that long duration therapy of antiepileptic drugs resulting in abnormality of bone metabolism such short stature, rickets disease, and osteomalacia [9]. The mechanism of oral antiepileptic drugs in abnormality of bone metabolism will be discussed.

This study has a purpose for understanding the nutritional characteristics of children with epilepsy that hospitalized in Sanglah Hospital, Denpasar. Thus, we can get essential information and has a basic knowledge for further study in management patient with epilepsy.

\section{Method and Material}

This research is an observational retrospective study using descriptive design with data will be shown as characteristics of nutritional profile among children with epilepsy that hospitalized in Sanglah Hospital Denpasar. The data was achieved, and conducted by taking samples from inpatient medical records in pediatric medical record installation in Sanglah Hospital Denpasar during January 2017 until December 2019 or until the minimum sample population fulfilled.

The inclusion criteria sample population of this study are children with epilepsy disease diagnosed by ILAE criteria 2017 [10], aged 1 month until 18 years old that hospitalized at Neurology ward in Sanglah Hospital. The exclusion criteria were children with lack of follow up, incomplete medical record and with underlying medical condition such congenital heart disease, immunocompromise disease (HIV, TBC, Leukemia and Malignancy). The sample size was calculated using proportion estimation samples with prevalence malnutrition in children with epilepsy was 52\%, the determination of accuracy was $10 \%$, and $\mathrm{Z}$ alpha was 1,96 . The minimum sample was obtained 95 subjects.

The data analysis was performed using SPSS $23^{\text {rd }}$ edition, to describe the characteristics of subjects and variables. The category variables are presented in terms of number and percentages. The data is presented in narrative and table form. This study has obtained ethical clearance from The Research Ethics Commision of the Faculty of Medicine Udayana, No: 1224/UN14.2.2.VII.14/LT/2020 and research permit from Sanglah Hospital, No: LB.02.01/XIV.2.2.1/209/8/2020.

\section{Result}

This study had collected minimum number of samples population, namely 95 samples within period of January 2017 until December 2019. Based on age, we obtained mean age of sample population was 5,4 years old ( $\mathrm{SD} \pm 4.3$ years), with majority subjects are male 60 children $(63,1 \%)$, and female 35 children $(36,9 \%)$. The epilepsy type were general epilepsy 59 children $(62,1 \%)$, focal epilepsy 23 children $(24,2 \%)$, and epilepsy focal combined general 13 children $(13,7 \%)$. Based on etiology, majority subjects is idiopathic 53 children $(55,8 \%)$, followed by etiology structural 30 children $(31,6 \%)$, etiology infection 8 children $(8.4 \%)$, and etiology immunology with metabolic 4 children (4,2\%).

Table 1. Charateristics of Subjects.

\begin{tabular}{ll}
\hline Characteristics & (N) \% \\
\hline Total subjects & 95 \\
Age (years) Mean \pm SD & $5.4 \pm 4.3$ \\
Gender & \\
Male & $(60) 63.1$ \\
Female & $(35) 36.9$ \\
Type of Epilepsy & \\
Epilepsy general & $(59) 62.1$ \\
Epilepsy fokal & $(23) 24.2$ \\
Epilepsy general fokal & $(13) 13.7$ \\
Etiology of Epilepsy & \\
Etiology idiopathic & $(53) 55.8$ \\
Etiology structural & $(30) 31.6$ \\
Etiology infection & $(8) 8.4$ \\
Etiology immunology & $(2) 2.1$ \\
Etiology metabolic & $(2) 2.1$ \\
\hline
\end{tabular}

The determination of nutritional status in this study, using waterlow method with weight for length/height using WHO 2006 by Z score or CDC curve 2000. The result revealed children with epilepsy with normal nutritional status were 53 children $(55,8 \%)$, mild protein energy malnutrition were 20 children $(21,1 \%)$, moderate protein energy malnutrition were 8 children $(8,4 \%)$, overweight were 8 children $(8,4 \%)$, obesity were 6 children $(6,3 \%)$, as attached in table 2 .

Table 2. Nutritional Status Children with Epilepsy in Sanglah Hospital.

\begin{tabular}{lll}
\hline Nutritional Status & Total Case & Percentage (\%) \\
\hline PEM Moderate & 8 & 8.4 \\
PEM Mild & 20 & 21.1 \\
Normal & 53 & 55.8 \\
Overweight & 8 & 8.4 \\
Obesity & 6 & 6.3 \\
Total & 95 & 100.0 \\
\hline
\end{tabular}

*PEM: Protein Energy Malnutrition.

The determination of nutritional status using waterlow method, we found mean of weight for length/height $99 \%$ ( $\mathrm{SD} \pm 18.8 \%$ ) thus we can conclude that majority of subjects population were normal nutritional status, as attached in table 2 .

Based on normal distribution curve as attached in figure 1, children with epilepsy that hospitalized in Sanglah Hospital with normal nutritional status, more than $50 \%$ of subjects population. 


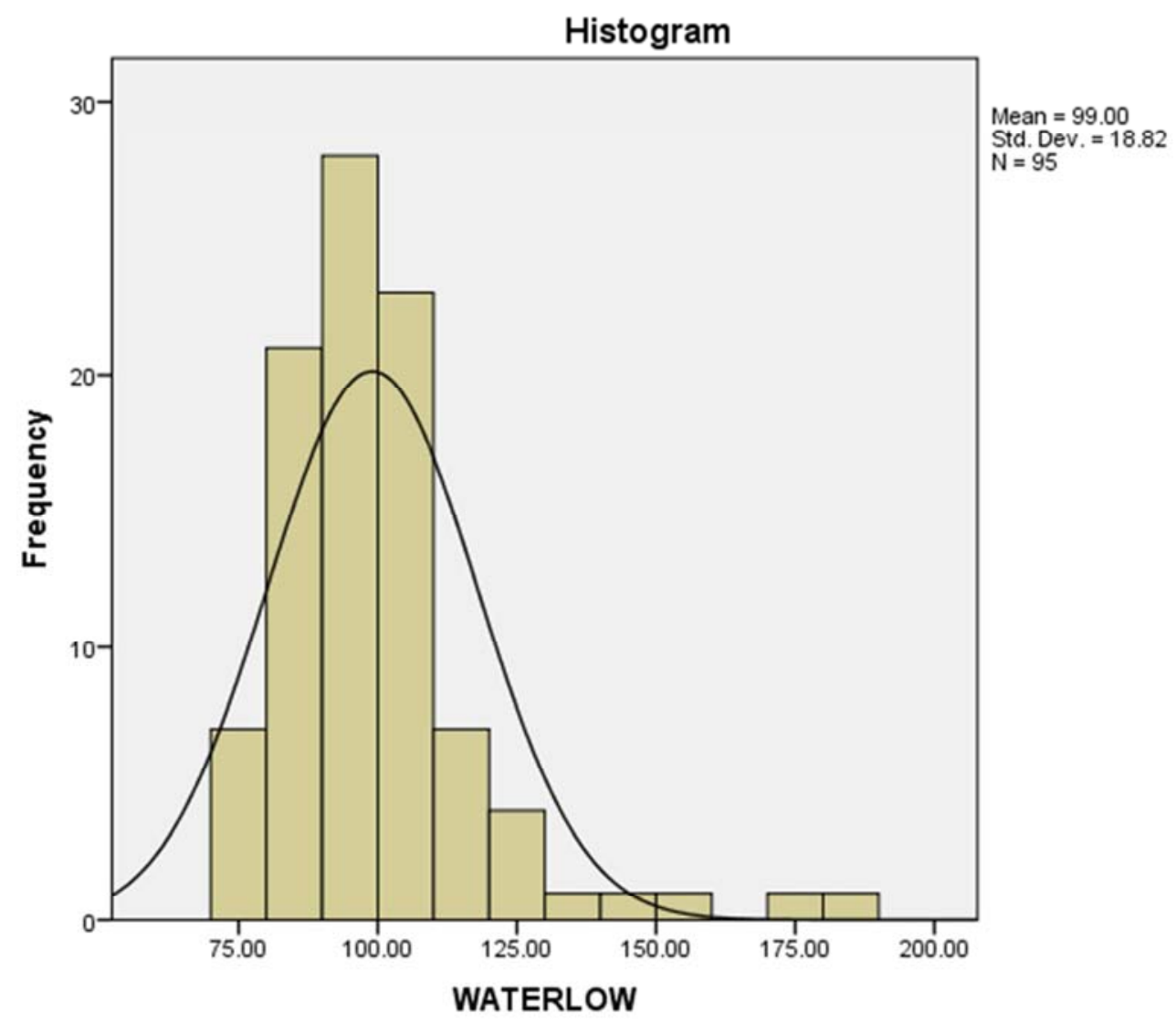

Figure 1. Distribution Normal Curve Weight for Length/Height (Waterlow Method).

The determination of body mass index (BMI) for this study was done and revealed mean BMI $17,8 \mathrm{~kg} / \mathrm{m}^{2}$ ( $\mathrm{SD} \pm 4,89)$. The determination of length/height for age was done and revealed that majority 71 subjects $(71,4 \%)$ had normal height status, 2 children were stunted $(2,1 \%), 22$ children were severe stunted $(23,2 \%)$, as attached in table 3 .

Table 3. Height Status For Children with Epilepsy in Sanglah Hospital

\begin{tabular}{lll}
\hline & Total & Percentage (\%) \\
\hline Normal & 71 & 74.7 \\
Stunted & 2 & 2.1 \\
Severe stunted & 22 & 23.2 \\
Total & 95 & 100.0 \\
\hline
\end{tabular}

\section{Discussion}

This study revealed that majority of children with epilepsy that hospitalized in Sanglah Hospital had normal nutritional status 53 children $(55,8 \%)$, and 71 children $(74,7 \%)$ had normal height status. There were some concern in this study that subjects with overweight and obesity nutritional status were 14 children and there were 24 children $(25,3 \%)$ had stunted condition

The growth status in children is affected by many factors such ethnicity, hormone, psychosocial, nutritional, chronic and chronic disease $[11,12]$. Study by Fernandez found that patient with epilepsy had probability for having overweight and obesity condition, $66,7 \%$, and $88,4 \%$, because of increasing of intake calorie and protein almost those subjects [13]. In this study, we found almost subjects $55,8 \%$ had normal nutritional profile because of adequate intake calorie and protein, meanwhile mild and moderate malnutrition were found because of presence underlying condition that affected oromotor function among subjects. Study by Suwarba found that abnormalities in growth and developmental milestones had been found approximately in $25 \%$ case which $39 \%$ case had cerebral palsy. Thus, the etiology symptomatic and structural epilepsy is a substance that can influence the nutritional outcome patient with epilepsy [14]. In this study, almost subjects with mild to moderate malnutrition had structural problem were $31,6 \%$, thus feeding management should be done by orogastric tube feeding. Moderate malnutrition occured in 8 subjects with infection meningitis condition 1 child, global developmental delayed 3 children, agenesis corpus callosum 1 child, hydrocephalus communicans 1 child, and neuroblastoma 1 child. For those subjects, the feeding management were using orogastric- 
nasogastric tube feeding, thus nutritional therapy could not be optimalized due to poor compliance of care giver or parents.

In this study, there were $14,7 \%$ subjects had overweight and obesity. Study by Elliot et al, found that patient with epilepsy has metabolic and cardiovascular complication [15]. It was affected by majority of female and types of anti epileptic drug that given to the patient [16]. Study by Teng Yeow Tan et al, found that long time management using antiepileptic drug can be associated with increasing risk of obesity and atherosclerosis [8]. It was caused by using oral antiepileptic drug in the long time, more than 12 months, could increase homocysteine serum and decrease folic acid serum. The medication that can affected the homocysteine and folic acid level are valproic acid, phenytoin, carbamazepine, and phenobarbital $[16,17]$. In this study, we found that 14 subjects that treated more than 12 months of duration oral antiepileptic drug namely phenytoin, carbamazepine, phenobarbital and valproic acid, as attached in Figure 2.

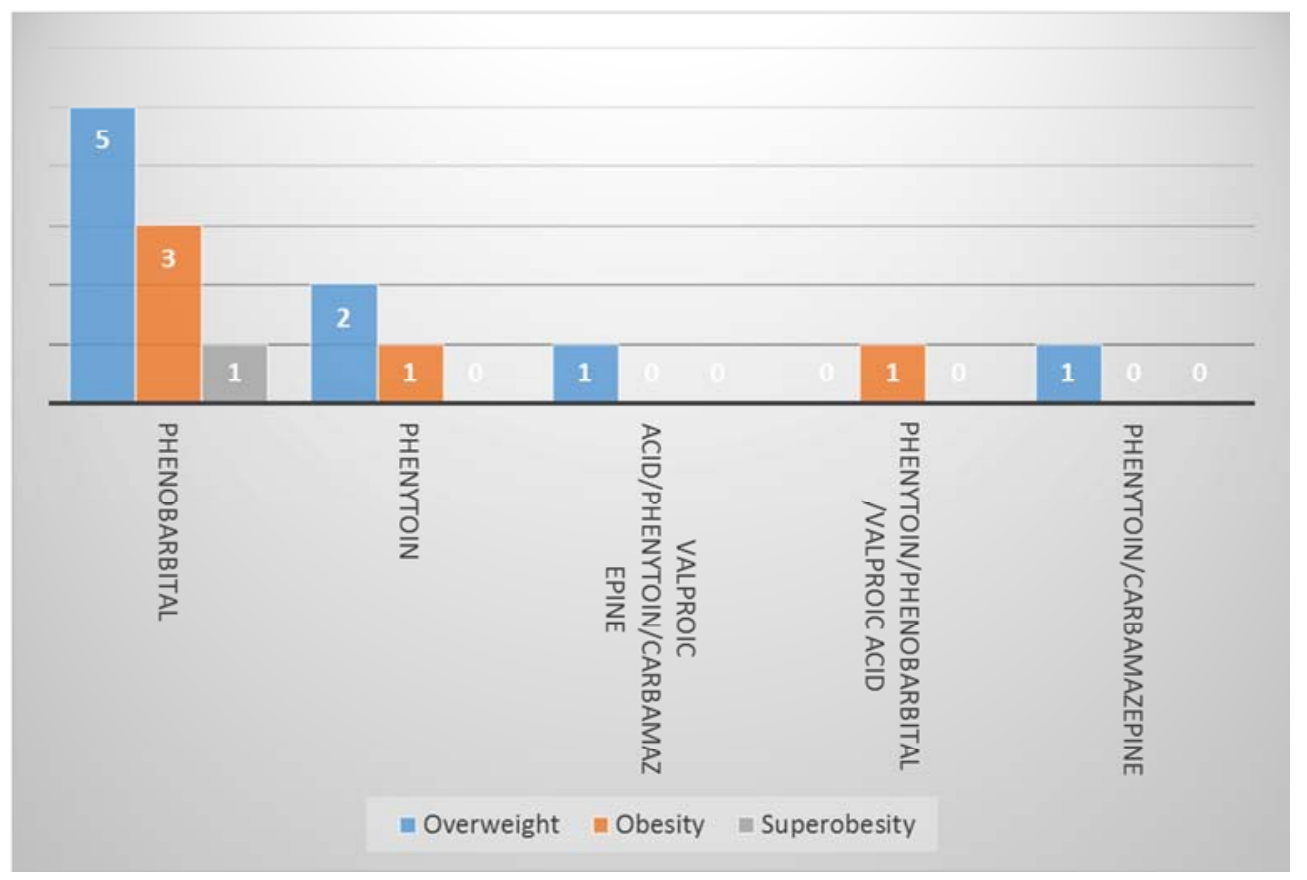

Figure 2. Type of Antiepileptic Drugs (>12 Months) and Nutritional Status.

Study by Verroti, et al, found that increasing metabolic effect was occurred in using valproic acid, with the same mechanism, valproic acid can decrease folic acid and homocysteine [17]. The high level of homocysteine can induce oxidation process, disruption of endothelial cell and finally resulting in atherosclerosis. The mechanism autooxidation can increase the production of relative oxygen and prothrombin inside the blood vessel. Study by Biton, et al, found that long time management of antiepileptic drugs can induce atherogenesis in obesity through the mechanism of microinflammation inside the blood vessel, that caused by high level of cholesterol, low density cholesterol [18]. It is strengthen by Gaspari that anti epileptic drugs may cause body weight changes which $75,6 \%$ recorded a weight gain using carbamazepine and valproic acid for anti epileptic drug [19].

The determination of anthropometric status based on height/length for age, there were 24 children $(25,3 \%)$ had stunted and severe stunted status with below third percentiles based on CDC curve 2000 or Z score less than 2 standard deviation [11]. As attached in figure 3, management monotherapy oral antiepileptic drugs was associated with stunted condtion were phenobarbital and phenytoin 8 children $(33,3 \%)$, carbamazepine 2 children $(11,1 \%)$, combination therapy (phenobarbital-carbamazepine, phenobarbital-valproic acid, phenytoin-valproic acid) 1 child each $(5,6 \%)$. Study by Valmadrid C, et al, showed that patient with epilepsy that was given oral antiepileptic drugs can increase the possibility of bone fracture, low bone mineral density, bone metabolic disease, and short stature [20]. In those study, 1000 subjects population adult and children were included, with $28 \%$ adult subjects and $41 \%$ children subjects has possibility of bone metabolic problem. It is strengthen by study of Guo, et al, in 2001, found that long management of epilepsy by using oral antiepileptic drugs can resulting in short stature, abnormality of teeth dentition, rickets disease, and osteomalacia [9]. The mechanism of bone abnormality is caused by increasing catabolism of vitamin $\mathrm{D}$, thus, calcium serum level is decreasing. Based on that study, determination of folic acid and calcium serum level can be cornerstone for understanding the correlation of short stature and epilepsy.

The strength of this study was 95 subject population were obtained which fulfilled the minimum estimation proportion sample calculation. It widely can represent and describe the characteristics of nutritional profile among children with epilepsy. In this study, we concern about not only the etiology of epilepsy but also the medication that might influence the nutritional status. 


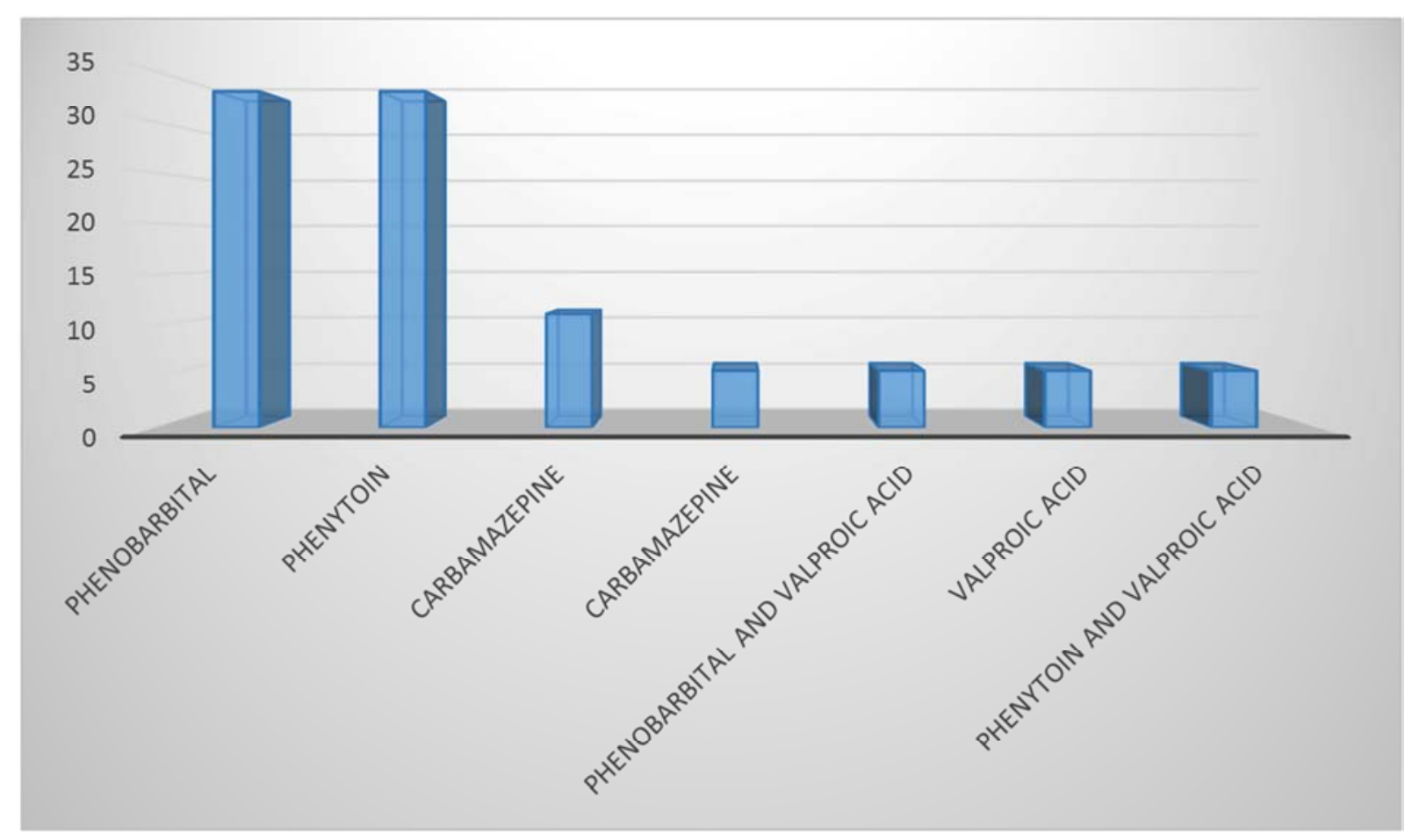

Figure 3. Type of Oral Antiepileptic Drugs with Outcome of Stunted Status (\%).

In this study, there were some limitation. The first limitation was we could not do the determination of folic acid level, homocysteine and calcium serum level among subjects because this method of study was retrospective. The second was anthropometric evaluation had been done only in one time, which it should be observed in the period of 1 to 3 months $[18,19]$.

We recommend for further study that the evaluation of nutritional status should be done prospectively every month to three months not only in one time for observing and analysing the correlation between antiepileptic drugs and nutritional status.

\section{Conclusion}

In this study, we can conclude that almost children with epilepsy that hospitalized at Sanglah Hospital had normal nutritional and height status. There were increasing number of subjects with obesity because of long duration of treatment with oral antiepileptic drugs, more than 12 months. There were underlying condition that can contribute the possibility of mild to moderate malnutrition, especially with etiology of structural, such agenesis corpus callosum, hydrocephalus communicans, and neuroblastoma. The role of homocysteine, folic acid, and calcium serum for affecting the nutritional status has been discussed. Using antiepileptic drugs in the long time can increasing homocysteine serum and decreasing folic acid and calcium serum level.

Thus, the determination of nutritional status, serum calcium, and folic acid serum should be done for evaluation of the possible complication such obesity, and short stature.

\section{Disclosure}

All the authors do not have any possible conflicts of interes.

\section{Acknowledgements}

None declared.

\section{References}

[1] Brodie MJ, Schachter SC, Kwan P. Epidemiology and prognosis. Fast Fact: Epilepsy Revised $5^{\text {th }}$ edition. Oxford: Health Press Limited. 2012; 9-11.

[2] Irawan M, Setyo H, Nelly A, et al. Epilepsi pada anak. Badan Penerbit Ikatan Dokter Anak Indonesia. 2016.

[3] Wieser HG dan Silfvenius H. Overview: Epilepsy surgery in developing countries. Epilepsia. 2000; 28-0.

[4] PERDOSSI. Kelompok Studi Epilepsi Perhimpunan Dokter Spesialis Saraf Indonesia. Pedoman tatalaksana epilepsi. Jakarta. 2011.

[5] Robert S F, Helen C, Norimichi H, Jacquelline F. Operational classification of seizures type by the International League Against Epilepsy: Position paper of the ILAE commission for classification and terminology. Epilepsia, 2017; 58 (4): 522530 .

[6] Damayanti R, Sri Sudaryati N, Yoga D, Conny F. Asuhan nutrisi pediatri. UKK Nutrisi dan Penyakit Metabolik. BP IDAI. 2011: 3 . 
[7] Aydin, Kartal. High rates of malnutrition and epilepsy: two common comorbidities in children with cerebral palsy. Turkish Journal of Medical Sciences. 2019; 49: 33-37.

[8] Teng Y, Cheng H, Hung Y. Long term antiepileptic drug therapy contributes to the acceleration of atherosclerosis. Epilepsia. 2009; 50 (6): 1579-1586.

[9] Guo CY, Ronen GM, Atkinson SA. Long-term valproate and lamotrigine treatment may be a marker for reduced growth and bone mass in children with epilepsy. Epilepsia 2001; 42: $1141-1147$

[10] Robert S, Helen C, Carol D, Jacquelline A, Sheryl R, Norimichi H, et al. Instruction manual fot the ILAE 2017 operational classification of seizure types. Epilepsia 2017; 58 (4): $531-542$.

[11] Jose R, Hardjoedi A, Aditiawati, Aman B, Nanis A, Eka A, et al. Perawakan pendek pada anak dan remaja di Indonesia. BP IDAI. 2017; 1-2.

[12] Hokken-Koelega ACS. Diagnostic workup of the short child. Horm Res. 2011; 76 (Suppl 3): 6-9.

[13] Fernandez R, Correa C, Bianchin M, Perry I. Anthropometric profile and nutritional intake in patients with epilepsy. Nutr Hosp. 2015; 32 (2): 817-22.
[14] IGN Made Suwarba. Insidens dan karakteristik klinis epilepsi pada anak. Sari Pediatri 2011; (13): 2.

[15] Elliot JO, Lu B, Shneker B, Moore J. Comorbidity, health screening, and quality of life among persons with a history of epilepsy. Epilepsy and Behaviour. 2009; 14 (1): 125-129.

[16] Tobias L, Dahl J, Lennart M, Bryan K. Evaluation of acceptance and commitment therapy for drug refractory Epilepsy: A Randomized Controlled Trial in South Africa A Pilot Study. Epilepsia, 2006; 47 (12): 2173-2179.

[17] Verroti A, Pascarella R, Trotta D, Giuva T. Hyperhomocysteinemia in children treated with sodium valproate and carbamazepine. Epilepsy Res. 2000; 41: 253257.

[18] Victor Biton. Effect of antiepileptic drugs on bodyweight. CNS Drugs. 2012; 17 (11): 781-91.

[19] Gaspari C, Guerreiro C. Modification in body weight associated with antiepileptic drugs. Neuro-Psiquiatr. 2010; 68: 2.

[20] Valmadrid C, Voorhees C, Litt B, Schneyer CR: Practice patterns of neurologists regarding bone and mineral effects of antiepileptic drug therapy. Arch Neurol 2001, 58: 1369-1374. 